\title{
Development of a Decision-Making Approach for Mass Deworming Campaigns on Intestinal Parasites among Primary School Children in Egypt
}

\author{
Noha Salah Abdelsamie Hassan ${ }^{1 *}$, Ghada Nasr Radwan ${ }^{2}$ \\ ${ }^{1}$ Public Health Officer, Preventive Medicine Sector, Ministry of Health and Population, Cairo, Egypt; ${ }^{2}$ Department of Community \\ Medicine, Professor of Public Health, Faculty of Medicine, Cairo University, Cairo, Egypt
}

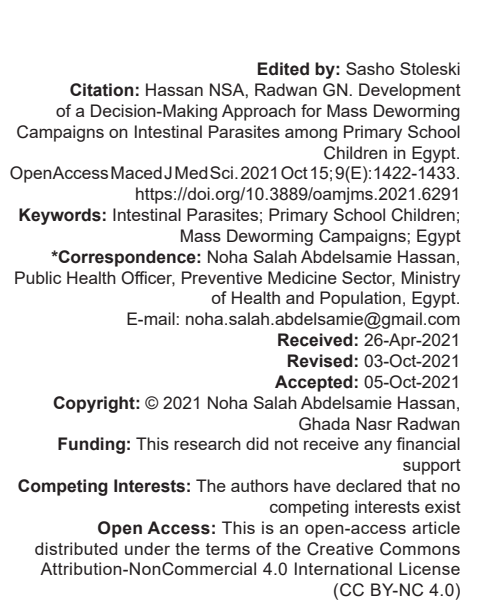

\section{Introduction}

Intestinal parasitic infections are among the most common infections worldwide. Epidemiological research carried out in different countries has shown that the social and economic situations of the individuals are important factors in the prevalence of intestinal parasites [1].

From the estimated global statistics, it was revealed that one third of the global population infected by intestinal parasitic infections; the majority lives in tropical and sub-tropical parts of the world [2].

Parasitic infections, caused by intestinal helminths and protozoan parasites, are among the most prevalent infections in humans in developing countries. In developed countries, protozoan parasites more commonly cause gastrointestinal infections compared to helminthes [3].

Helminths are commonly referred to as parasitic worms and can include the following groupings: roundworms (nematodes), such as
Ascaris lumbricoides and Strongyloides stercoralis; whipworms, such as Trichuris trichiura; hookworms, such as Necator americanus; flukes (trematodes), such as Facsiola hepatica and Schistosoma mansoni; and cestodes (tapeworms) [4].

Many of these helminth parasites are soiltransmitted and cause gastrointestinal infections following ingestion of pasture or water contaminated with their eggs. The schistosomes, in contrast, can establish chronic infection within the host's bloodstream. Infections with helminth parasites often cause significant pathology, for example, as they migrate through host tissues following infection through the skin (e.g. schistosomes), or feed on the gut epithelium (e.g. Trichuris spp.) [5].

The most common intestinal protozoan parasites are: Giardia intestinalis, Entamoeba histolytica, Cyclospora cayetanenensis, and Cryptosporidium spp. The diseases caused by these intestinal protozoan parasites are known as giardiasis, amoebiasis, cyclosporiasis, and cryptosporidiosis, respectively, and they are associated with diarrhea [6]. 
G. intestinalis is the most prevalent parasitic cause of diarrhea in the developed world, and this infection is also very common in developing countries, while Giardia lamblia is more common in developing countries. Amoebiasis is the third leading cause of death from parasitic diseases worldwide, with its greatest impact on the people of developing countries. Cryptosporidiosis is becoming most prevalent in both developed and developing countries among patients with AIDS and among children aged $<5$ years [7].

Intestinal parasitic infections are responsible for considerable morbidity and occasional mortality among the infected population throughout the world, with more than 39 million disability adjusted life years are linked to Intestinal Parasitic Infections which are responsible for huge financial burden, and although age is not a factor, children are observed to be most affected by parasitic infestation [8]. Furthermore, parasitic infection in pregnant and women in reproductive age can be responsible for intrauterine growth retardation, micro and macronutrient deficiency, and low birth weight [9].

Parasitic infections are governed by behavioral, biological, environmental, nutritional and socioeconomic and health systems factors. Local conditions, including access to and quality of domestic and village infrastructure, economic factors such as disposable income, employment and occupation, and social factors such as education, influence the risk of infection, disease transmission, and associated morbidity and mortality [10].

It is generally acknowledged that parasitic diseases are the most common among children under the age of five; as they are more vulnerable to soiltransmitted helminthic infections than adults [11]. They carry the heaviest burden of the associated morbidity, due to their unrestrained habits of playing or handling of infested soils, eating with soiled hands, unhygienic toilet practices, drinking, and eating of contaminated water and food [12].

In Egypt, intestinal parasitic infection in children is a common public health problem; in all governorates it was identified among infants, preschool and school children. Although the reported prevalence rates in different parts of Egypt vary considerably from one study to another, nearly $27 \%$ of the children are suffering from intestinal parasites according to a study conducted in Assuit Governorate. Various prevalence rates of soil-transmitted helminthes and protozoa have been reported among children in different Egyptian Governorates [13].

Mass drug administration against intestinal parasites has proved to be a cornerstone in combating these infections in endemic areas, but this approach does not necessarily prevent reinfection. Additional public health measures, such as health education, are required for sustained, integrated control of the infection [14].
In commitment to the London Declaration on Neglected Tropical Diseases and the contribution of donated drugs from pharmaceutical companies, over 5.5 billion tablets have been donated providing 3.5 billion treatments since the launch of the London Declaration in 2012. In 2014, 1.45 billion treatments were made available to endemic countries, representing a $36 \%$ increase since 2011 [15].

The Egyptian Ministry of Health and Population has adopted mass deworming campaigns with the support of the World Health Organization (WHO) as a prevention-and-control measure against intestinal parasitic infestation in primary school children starting from 2016. This study is to measure the impact of these campaigns on the burden of intestinal parasites infestation among primary school children and whether these campaigns to be continued or ceased.

\section{Methodology}

The study was conducted in 8 Governorates from both Lower and Upper Egypt (Portsaid - Al Sharqia - KafrAlsheikh - Al Bihera - Giza - BeniSweif Menia - Assuit). The study sample was primary school children registered as recipients of the deworming tablets during the national deworming campaigns in 2017 in the selected 8 Egyptian Governorates, and the administrative and technical staff running the national mass deworming campaigns in 2017 in the same Governorates.

The study was three-phased; beginning with a desk review on national efforts in combating intestinal parasites, the second phase was a cross-sectional study on 522 primary schools children who received the mass deworming medicines and 198 personnel of attending staff of the national mass deworming campaign of 2017. The last phase was dedicated to development of a decision-making approach for guidance of future mass deworming campaigns.

The cross-sectional study was conducted through assisted questionnaire forms for children, and a semi-structured interviews with staff members. All collected data were revised for completeness and logical consistency, where pre-coded data were entered on the computer using a database developed for data entry on Microsoft Office Excel Program for Windows 10. Data were then imported to be analyzed on Epi Info edition 7 (Epi Info ${ }^{\mathrm{TM}} 7$ ).

A research proposal was submitted to the Department of Community Medicine at the Faculty of Medicine of Cairo University for approval on this study, and an official approval on this study was granted from the Research Ethics Committee at Faculty of Medicine, Cairo University prior to commencement of 
the research, where all ethical considerations needed for this research were thoroughly followed.

\section{Results}

The department responsible for the activities of prevention and control of intestinal parasites on the governmental level is the General Administration of Schistosomiasis and Intestinal Parasites, which is one of the three General Administration of the Central Administration of Endemic Diseases, which is one of the four major four Central Administration of the Preventive Medicine Sector of the Egyptian Ministry of Health and Population, which is considered the leading governmental sector of preventive medicine activities in Egypt (Figure 1).

In addition to the Ministry of Health and Population, there are some Non-Governmental Organizations such as civil society associations and International Organizations such as the United Nations Children's Fund (UNICEF) and the WHO that contribute to these activities either by finical aid, medicines donations, and/or technical support. In addition, there are national and international research bodies that conduct several researches on the issue of parasitic infections. However, they perform through coordination with the Ministry of Health and Population and/or under its supervisory umbrella.

The activities of the General Administration of Schistosomiasis and Intestinal Parasites could be administratively divided into Anti-Schistosomiasis activities and Anti-Intestinal Parasites activities, this study focused on the measures taken to combat intestinal parasites which are as follows (Figure 2):

In reference to the workforce; physician and lab technicians are the main key players, starting by the physician for initial diagnosis and sending the patient for laboratory analysis where the role of lab technician is most important, then the patient returns to the physician for treatment and follow-up. However, there has been recent reported shortage in physicians throughout Egypt; where the physician density in Egypt was measured to be 0.5 in 2018 by the World Bank [16].

The positive cases are given the necessary treatment and the diagnoses are written in a special record for intestinal parasites and Schistosomiasis which is regularly monitored by the health district and directorate, in addition to the inspection done by

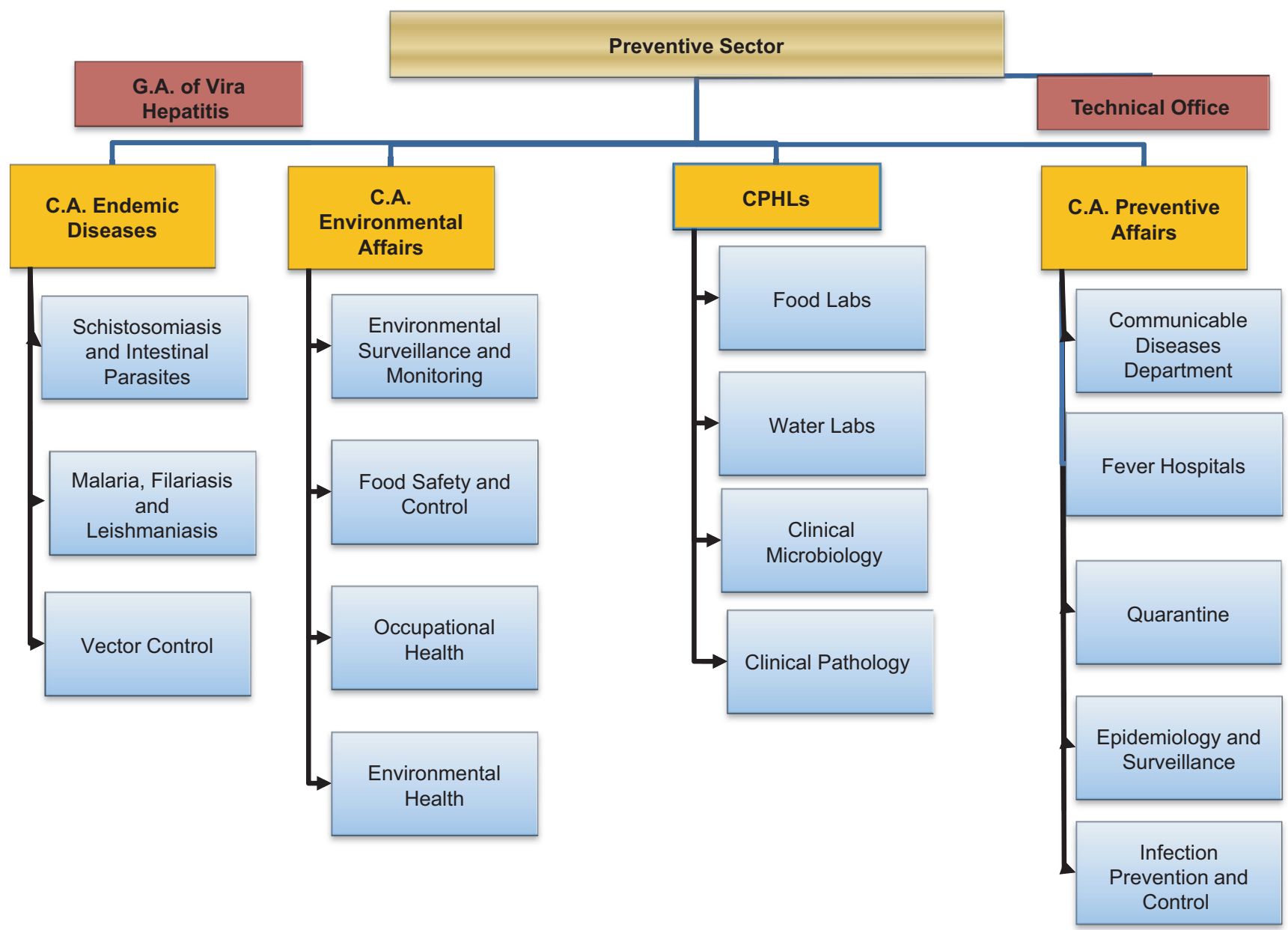

Figure 1: Hierarchy of the Preventive Medicine Sector, Ministry of Health and Population, Egypt 


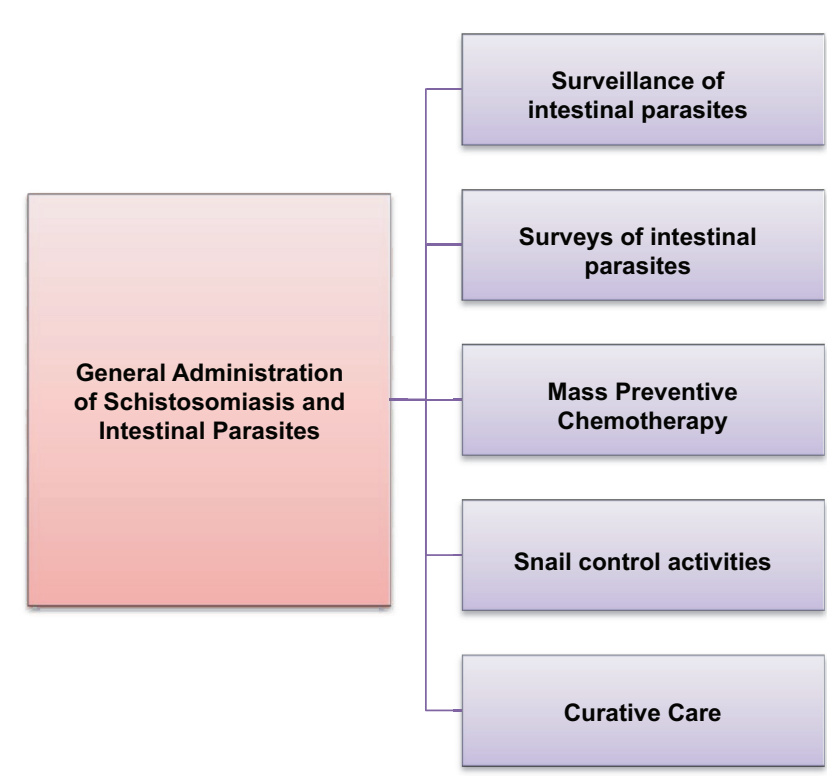

Figure 2: Routine activities of the General Administration of Schistosomiasis and Intestinal Parasites directed toward combating intestinal parasites. Ministry of Health and Population, Egypt

the General Administration of Schistosomiasis and Intestinal Parasites team itself, where they have a special monitoring and evaluation approach which dictates that a $10 \%$ sample of the microscopicallyexamined stool slides are kept for inspection, technical evaluation, and quality assurance.

Furthermore, the National Electronic Diseases Surveillance System has access to the data gathered by the General Administration of Schistosomiasis and Intestinal Parasites in their own surveillance either for intestinal parasites or Schistosomiasis. However, there is some sort of discrepancy between the numbers gathered by the two aforementioned parties.

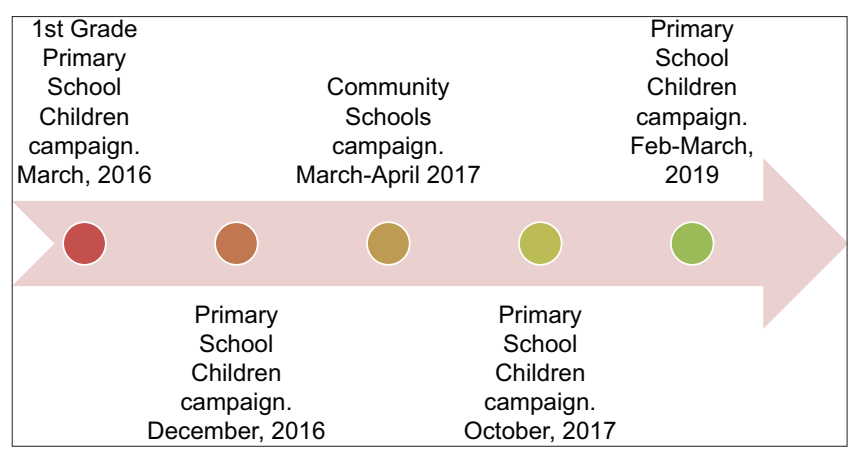

Figure 3: The mass deworming campaigns conducted by the Egyptian Ministry of Health and Population from 2016 till 2019 in chronological order

Regarding routine surveys for intestinal parasites; there are two nationally-adopted approaches as follows:

- $\quad$ School entry surveys (where stool samples are collected from students in entry classes, e.g. first grade primary school students)

- Specific surveys (for endemic foci, or foci of high reported number of positive cases).
According to the $\mathrm{WHO}$, preventive chemotherapy can dramatically reduce the burden of parasitic infections caused by soil-transmitted Helminth infections. Therefore, The Ministry of Health and Population has started to adopt the mass deworming campaigns as a recommended measure in prevention and control of intestinal parasitic infection in school children which is one of the categories listed as target groups for preventive chemotherapy against intestinal parasites and specifically soil-transmitted Helminth infection as was mentioned by the WHO Guideline [17].

The deworming medicines came as a donation from global pharmaceutical companies pursuant to London declaration on Neglected Tropical Diseases launched in 2012; the deworming medicines used in the Egyptian campaigns were chewable tablets in the following concentrations:

\section{- $\quad$ Albendazole (200 mg and $400 \mathrm{mg}$ ) \\ - $\quad$ Mebendazole (500 mg).}

The Ministry of Health and Population first started its mass deworming campaigns as a pilot for the first grade primary school children in March 2016 with the cooperation and support of the WHO where the first grade primary school children were given two doses of Albendazole $400 \mathrm{mg}$ tablets, separated by 2 weeks apart, that came as a donation from the WHO. This pilot campaign targeted total of $(2,055,688)$ children of first grade primary school throughout Egypt with coverage of $(96.4 \%)$ for the first does and $(98.1 \%)$ for the second dose (Table 1).

Table 1: Mass Deworming Campaign for first grade primary school children coverage rates, March 2016

\begin{tabular}{llllll}
\hline Target number of children & \multicolumn{2}{l}{ First dose } & & \multicolumn{2}{l}{ Second dose } \\
\cline { 2 - 3 } \cline { 5 - 6 } & Treated & Coverage & & Treated & Coverage \\
\hline 2055688 & 1980708 & $96.4 \%$ & & 2017530 & $98.1 \%$ \\
\hline
\end{tabular}

Then, in December 2016 the Ministry of Health and Population launched a large-scale national mass deworming campaign for all primary school children (from first till sixth grade classes) with target total of $(12,454,000)$ children. This campaign used one dose of Mebendazole chewable tablets and with coverage of $(97.1 \%)$. Another national deworming campaign took place in October 2017, again for all primary school children throughout Egypt, the campaign targeted (12.482.000) Children with a coverage rate of (98.8\%).

Although the campaigns did cover all primary schools in Egypt either governmental or private, the community schools (schools where children that are not enrolled in regular schools are obtaining education) were not included. Therefore, the Ministry of Health and Population cooperated with the World Food Program and they launched a mass deworming campaign for community schools where all community schools throughout Egypt were targeted and over 135,000 children were administrated two doses of Albendazole $200 \mathrm{mg}$ separated by 2 weeks apart in March and April 2017 (Table 2). 
Table 2: National Mass deworming campaigns for community schools coverage rates. Ministry of Health and Population, Egypt

\begin{tabular}{|c|c|c|c|c|c|}
\hline \multirow[t]{2}{*}{ No. of Schools } & \multirow[t]{2}{*}{ Target No. of Children } & \multicolumn{2}{|c|}{ First dose } & \multicolumn{2}{|c|}{ Second dose } \\
\hline & & Treated & Coverage & Treated & Coverage \\
\hline 5121 & 134726 & 130983 & $97.2 \%$ & 128867 & $95.7 \%$ \\
\hline
\end{tabular}

The Egyptian Ministry of Health was intending to run a mass deworming campaign each year, which started in 2016, continued in 2017 and was planned to continue in 2018. However, the timing of mass deworming campaigns came concomitant with the Presidential initiative "100 Million Healthy Lives" against hepatitis $\mathrm{C}$ virus and non-communicable diseases, therefore; the 2018 campaign was postponed till February 2019 and included 16 governorates with a target number of approximately 8.5 million primary schoolchildren. Where the second phase started from 19 to 28 March 2019 and included 11 governorates with a coverage rate of $(101.2 \%)$.

Here is a graph for mass deworming campaigns starting in 2016 till 2019 in a chronological order (Figure 3).

Despite the fact that all the deworming medicines came as a donation from global pharmaceutical companies through the $\mathrm{WHO}$, mass deworming campaigns were still costly when it comes to operational costs. In the next (Table 3) breakdown for the operational costs of the mass deworming campaigns of 2016 and 2017 are highlighted hereunder.

Table 3: Breakdown of operational costs of both 2016 and 2017 mass deworming campaigns as provided by the Ministry of Health and Population

\begin{tabular}{|c|c|c|}
\hline Parameters & 2016 & 2017 \\
\hline Operational and & $\sim 2,878,000$ EGP provided by & $\sim 4,500,000 \mathrm{EGP}$ \\
\hline Inspection Teams & $\begin{array}{l}\text { MoHP }+1,500,000 \text { EGP provided } \\
\text { by UNICEF }\end{array}$ & provided by UNICEF \\
\hline Awareness materials & $\begin{array}{l}\text { 200,000 EGP provided by } \\
\text { UNICEF }\end{array}$ & $\begin{array}{l}\sim 145,000 \text { EGP } \\
\text { provided by MoHP }\end{array}$ \\
\hline $\begin{array}{l}\text { Airing (TV and Radio } \\
\text { Spots) }\end{array}$ & $\sim 500,000$ EGP provided by MoHP & $\begin{array}{l}\text { 500,000 EGP } \\
\text { provided by MoHP }\end{array}$ \\
\hline
\end{tabular}

Although, the WHO and UNICEF provided a substantial support in terms of deworming medicines and covering of operational costs, respectively, still the Ministry provided almost 2 and half million Egyptian Pounds to run the campaigns that were not basically enrolled in the original budget signed each year, therefore; the financial credentials of these campaigns usually take time till they are approved.

In reference to the impact of these mass campaigns; the General Administration of Schistosomiasis and Intestinal Parasites at the Ministry of Health and Population conducted a survey in eight selected Governorates before and after the national mass deworming campaign conducted in December 2016 to assess the prevalence of intestinal parasites among school children targeted with the mass deworming medicine (Mebendazole) in this campaign (Table 4).

As previewed in the above table, the prevalence of Intestinal parasites among the tested samples of the
Table 4: Prevalence of intestinal parasites tested in stool samples of primary school children in eight Governorates before and after 2016 Mass deworming campaign (MoHP, 2018)

\begin{tabular}{|c|c|c|c|c|c|c|}
\hline \multirow[t]{2}{*}{ Governorate } & \multicolumn{3}{|c|}{ Before camp. Oct. 2016} & \multicolumn{3}{|c|}{ After camp. Mar. 2017} \\
\hline & $\begin{array}{l}\text { Examined } \\
\text { No. }\end{array}$ & $\begin{array}{l}\text { +ve } \\
\text { cases }\end{array}$ & $\begin{array}{l}\text { Prevalence } \\
\%\end{array}$ & $\begin{array}{l}\text { Examined } \\
\text { No. }\end{array}$ & $\begin{array}{l}\text { +ve } \\
\text { cases }\end{array}$ & $\begin{array}{l}\text { Prevalence } \\
\%\end{array}$ \\
\hline Port Said & 312 & 45 & 14.4 & 293 & 24 & 8.2 \\
\hline Sharkia & 302 & 33 & 10.9 & 372 & 19 & 5.1 \\
\hline Kafr ElShiekh & 274 & 60 & 21.9 & 400 & 5 & 1.3 \\
\hline Behira & 294 & 78 & 26.5 & 300 & 19 & 6.3 \\
\hline Giza & 499 & 123 & 24.6 & 590 & 3 & 0.5 \\
\hline Bani Swif & 311 & 23 & 7.4 & 300 & 1 & 0.3 \\
\hline Menia & 300 & 51 & 17 & 300 & 2 & 0.7 \\
\hline Assuit & 385 & 149 & 38.7 & 405 & 9 & 2.2 \\
\hline Total & 2677 & 562 & 21 & 2960 & 82 & 2.8 \\
\hline
\end{tabular}

target population (primary school children) was $21 \%$. Later, in March 2017 the stool results of the examined post-campaign sample showed a remarkable decrease in prevalence which was $2.8 \%$ after mass drug administration of Mebendazole $500 \mathrm{mg}$ [18].

Despite the dramatic decrease in the overall prevalence of intestinal parasites among the assessed Governorates, this $2.8 \%$ prevalence did not last; as according to the data retrieved from the Ministry of Health and Population in the survey conducted before and after the national mass deworming campaigns conducted in October 2017 (almost a year after the launch of the first campaign), it was observed that the overall prevalence of intestinal parasites in the assessed Governorates was $10.2 \%$. However, regardless of the pre-campaign prevalence, the campaign came successful in decreasing the intestinal parasitic infection prevalence to drop to $2.5 \%$ which is evidence to the effectiveness of the administrated medicine, Mebendazole $500 \mathrm{mg}$ (Table 5).

Table 5: Prevalence of intestinal parasites among primary school children before and after the 2017 deworming campaign (MoHP, 2018)

\begin{tabular}{lllll}
\hline Governorates & $\begin{array}{l}\text { Number of } \\
\text { examined children }\end{array}$ & $\begin{array}{l}\text { Prevalence of IPIs } \\
\text { Before campaign }\end{array}$ & & $\begin{array}{l}\text { Prevalence of IPIs } \\
\text { After campaign }\end{array}$ \\
\cline { 3 - 3 } & & $1-12 / 10 / 17$ & $6-15 / 3 / 18$ \\
\hline Port said & 600 & 7.2 & 4.7 \\
Sharkia & 600 & 10.3 & 4.2 \\
Dakahlia & 600 & 7.5 & 0 \\
Kafr EIShiekh & 580 & 7 & 1.9 \\
Behira & 609 & 11.3 & 2.6 \\
Giza & 600 & 9.3 & 0 \\
Bani Swif & 600 & 14 & 0 \\
Menia & 600 & 18.7 & 7.5 \\
Assuit & 600 & 4.7 & 2 \\
Sohag & 600 & 10.2 & 1.8 \\
Total & 5989 & & 2.5 \\
\hline
\end{tabular}

As regard to the cross sectional study; 522 primary school children were questioned by assisted self-administrated questionnaire in simple Arabic language, with supervision and assistance of their teachers and sometimes the school health official whenever possible.

Out of the 522 children who voluntarily participated in this study; 282 children were females (54\%) and 240 children were males (46\%).

The age of the participating school pupils were ranging from 6 to 13 years, with a mean of 10 years $(S D=1.8)$, the percentage distribution of age among the studied samples is illustrated in (Figure 4). 


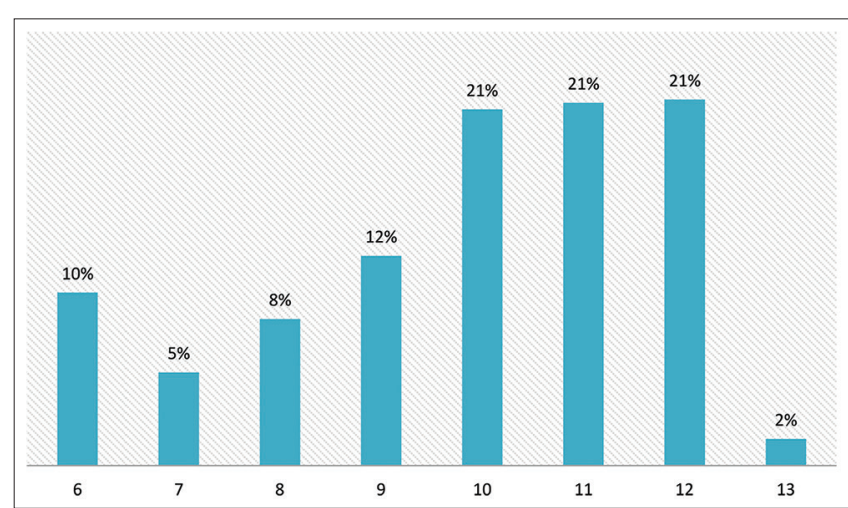

Figure 4: Age distribution of the primary school childr en of this study, mass deworming campaign 2017

Of this population sample, 375 of the participating children were from rural areas $(72 \%)$, while 147 of them were from urban areas $(28 \%)$ in the 8 selected Governorates (Figure 5).

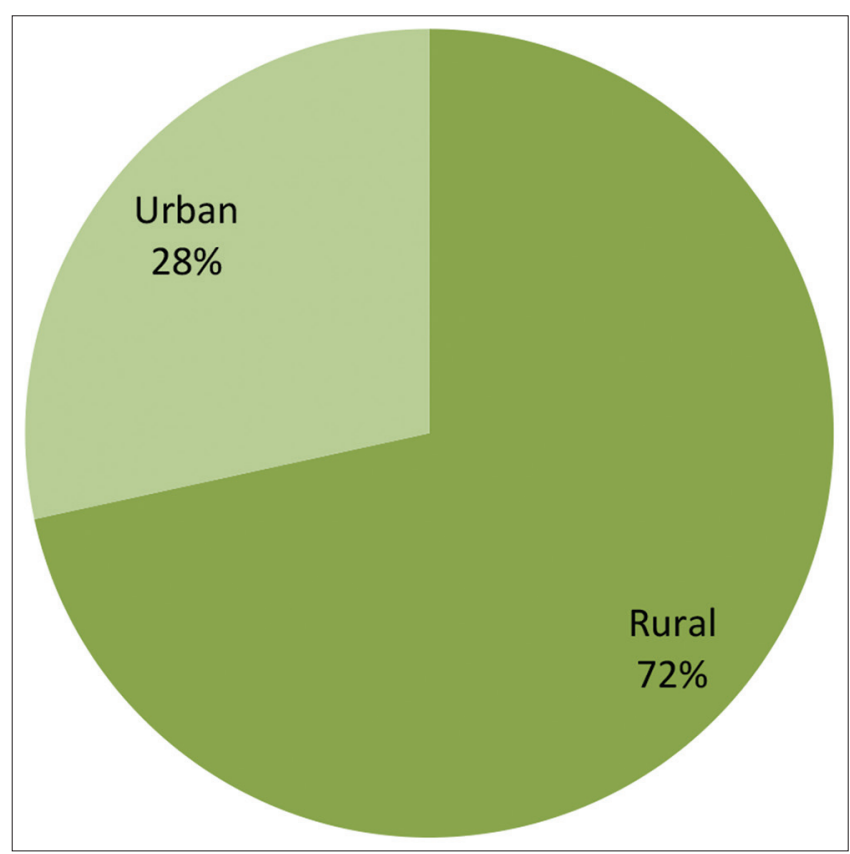

Figure 5: Percentage distribution of primary school children according to residence, Mass deworming campaign 2017

All the participating children confirmed taking the tablet Mebendazole $500 \mathrm{mg}(100 \%)$, but it was difficult to identify if they swallowed or chewed the given tablets as was recommended and instructed to them; as some of the children reported in their comments that the tablet was too big, especially for younger children in this sample.

518 children reported that intestinal parasites (explained as worms) were dangerous (99.4\%); that is why they were taking these tablets to kill them, although 429 of them who actually knew what intestinal parasites were $82.3 \%$.

Regarding general knowledge and understanding of what intestinal parasites are, girls were more knowledgeable about intestinal parasites than boys who participated in this study. With 450 of girls $(86.1 \%)$ knew what intestinal parasites are, while 406 of boys $(77.9 \%)$ had such knowledge (Figure 6$)$.

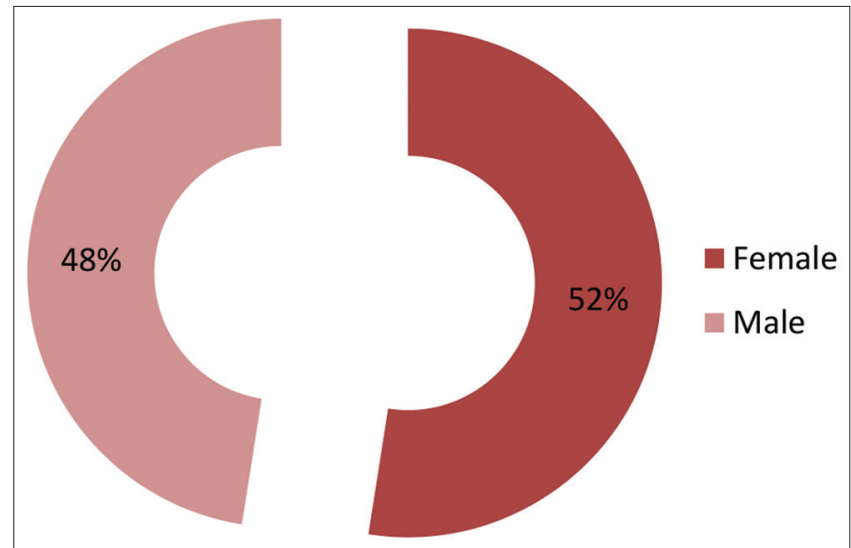

Figure 6: Percentages of girls versus boys according to knowledge of intestinal parasites, mass deworming campaign 2017

Knowledge about parasites was not much different among school children from rural or urban settings, with 440 of school children who knew what intestinal parasites were from schools in urban areas (84.4\%), while 425 of rural school children knew about parasites were $81.5 \%$.

Knowledge about parasites increased with age where 135 of children from the age group (6-9) years knew what intestinal parasites were, which counts for $26 \%$ of the study sample. On the other hand, 295 of children from the older age group (10-13) years knew what intestinal parasites were, which is about $(57 \%)$ of the study sample (Figure 7).

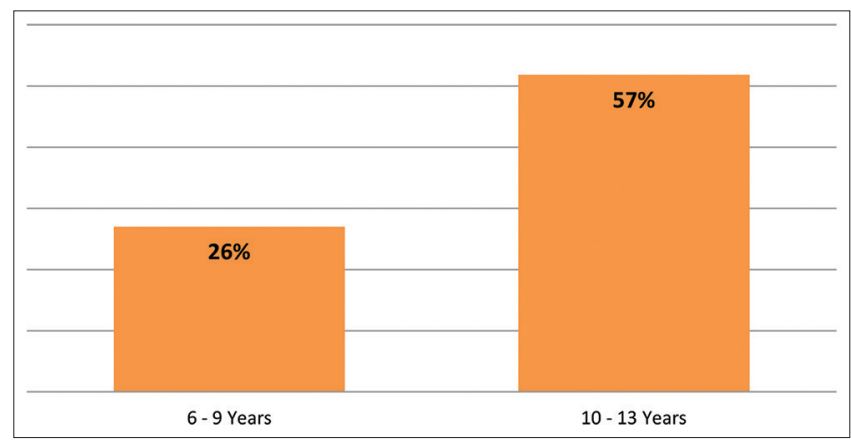

Figure 7: Distribution of percentage of knowledge about intestinal parasites among primary school children according to age groups, Mass Deworming Campaign 2017.q

Knowledge about intestinal parasites varied according to Governorates, where Lower Egypt Governorates scored higher than Upper Egypt Governorates (Figure 8).

\section{Receipt of health education}

Out of the 522 primary school children taken into this study, $99.2 \%$ confirmed that they had received health education either by school nurse or one of the local health authority personnel.

All Governorates listed in this study confirmed $100 \%$ health education coverage before commencing the mass deworming campaigns, except for Beni 


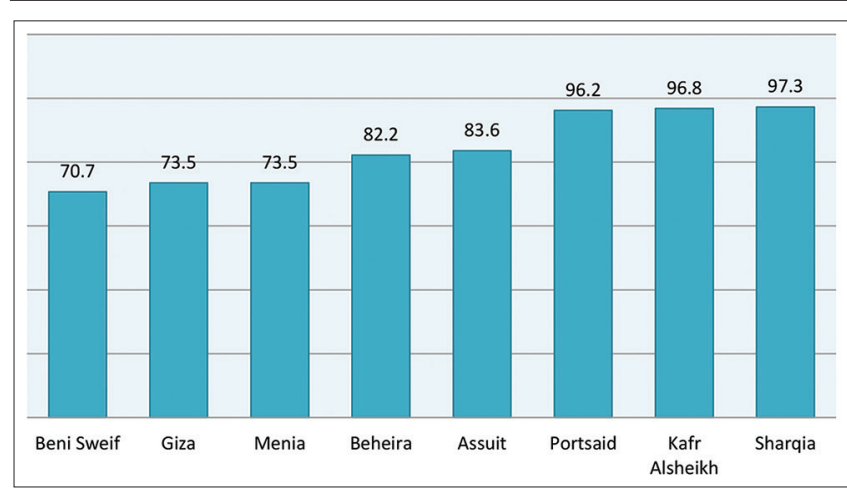

Figure 8: Distribution of knowledge percentages among primary school children per Governorate, Mass Deworming Campaigns 2017.

Sweif where around 95\% confirmed receipt of health education before campaign (Figure 9).

As for personal and hand hygiene practices, all the school children who participated in this study $(100 \%)$ were aware of the importance of basic hand and personal hygiene practices to prevent illnesses and infectious diseases.

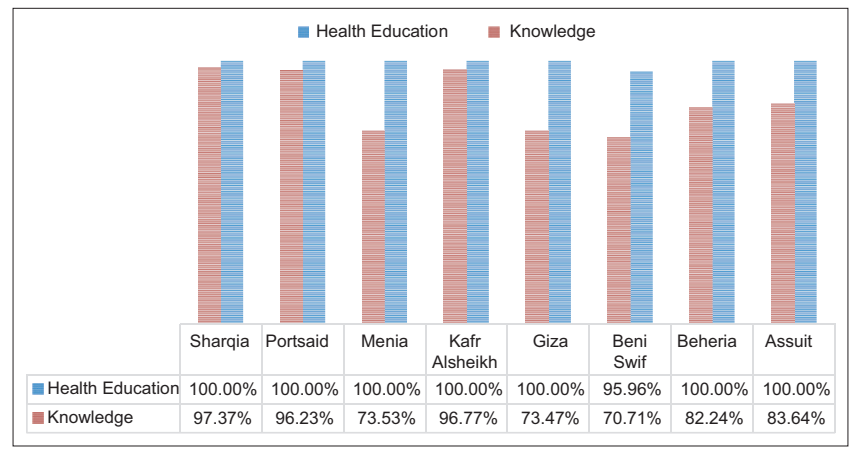

Figure 9: Distribution of percentages of knowledge of intestinal parasites and health education receipt before the 2017 mass deworming campaign per governorate

However, when children were asked more specifically about certain measures; such as regular nail trimming, hand wash after toilet, and use of soap with water to clean hands their answers varied according to several factors such as soap availability, water availability, and gender.

Although, 512 of the participating children (98.1\%) reported that there is a water supply in their schools lavatories, only 74 of the participating children (14.2\%) confirmed soap availability at the lavatories (Figure 10).

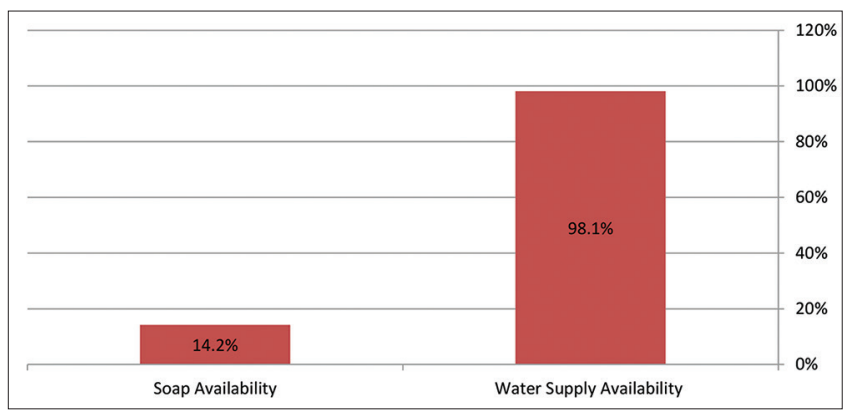

Figure 10: Water availability versus soap availability among primary schools, mass deworming campaign 2017
In reference to availability of soap at schools lavatories according to being either in urban or rural settings, 31 (out of 147) of the participating children from schools in urban areas $(21 \%)$ reported that there is soap in the school lavatories, while 43 (out of 375 ) of the participating children from schools in rural settings $(11.5 \%)$ that confirmed availability of soap at schools lavatories. A Chi-square test of independence was performed to examine the relation between presence of soap in schools lavatories and residence of the child, either urban or rural, and the relationship between these variables was significant with $p=0.00553$.

\section{Campaign staff interviews}

168 health-care team members were interviewed from the selected Governorates. The interviewed staff members were medical doctors, dentists, pharmacists, nurses, and lab technicians. Years of experience were ranging from 2 years to over 40 years of experience in the field of preventive medicine and/or healthcare in general.

All the interviewed health team members (100\%) confirmed that there have several preparatory meetings before the campaigns, where most of them were highly specific to the campaign itself, and some of these meetings were multi-sectorial with representatives from the Governorates, Central Administration of Endemic Diseases at MoHP, Ministry of Education and others.

When the interviewed health team members were interviewed about, whether the national deworming campaigns were supposed to continue or not, all of them $(100 \%)$ answered with yes, as they believed that this campaign is very important to decrease the prevalence of intestinal parasites in addition to raising awareness about intestinal parasitic infestation in general either among primary school children or the public in general.



Figure 11: Percentage of Health Care Team (HCT) members who reported some disadvantages (cons) of the Mass Deworming Campaign against Intestinal Parasites, 2017

Regarding cons of this campaign; approximately one-third of the interviewed health team members stated that they can hardly find a negative side to these mass deworming campaigns (Figure 11). However, 109 
of the participating staff, almost (65\%), mentioned some downsides of this campaign such as lack of cooperation with some school managers although all the schools were notified prior to these campaigns with sufficient timeline $(16.7 \%)$. Furthermore, the interviewed health team members mentioned this campaign should have received a better advertisement through $\mathrm{TV}$ and radio spots for example (7.14\%) (Table 6).

Table 6: The reported disadvantages of the mass deworming campaign as reported by the health team running the campaign at the selected Governorates

\begin{tabular}{ll}
\hline $\begin{array}{l}\text { The Reported cons of the mass deworming campaign as reported by } \\
\text { the Health Team running the campaign at the selected Governorates }\end{array}$ & Percentage \\
\hline $\begin{array}{l}\text { Difficulty in swallowing/Chewing the tablets (very big) for the young } \\
\text { children ( } 6 \text { and } 7 \text { years old) }\end{array}$ & 2.38 \\
$\begin{array}{l}\text { Weak involvement of health insurance association } \\
\text { Lack of transportation means for the health team members running }\end{array}$ & 2.38 \\
the campaign & 2.38 \\
$\begin{array}{l}\text { No plastic cups for water administration for children, especially for } \\
\text { those who didn't bring or didn't have a water flask with them }\end{array}$ & 2.38 \\
$\begin{array}{l}\text { The reported few number of community health workers, and school } \\
\text { nurses. The current team has been pushed to its limits, been assigned }\end{array}$ & 4.76 \\
$\begin{array}{l}\text { with more than one school } \\
\text { Lack of advocacy for the campaign either in TV or Radio }\end{array}$ & 7.14 \\
$\begin{array}{l}\text { Resistance from some parents to allow their children to take the tablet } \\
\text { Timing of the campaign came across other campaigns which was a }\end{array}$ & 11.90 \\
source of confusion to health teams and schools, also a burden on \\
health teams \\
$\begin{array}{l}\text { Lack of cooperation from some schools' managers and administrative } \\
\text { staff }\end{array}$ \\
\begin{tabular}{l} 
No reported disadvantages \\
\hline
\end{tabular}
\end{tabular}

The interviewed health team members suggested that extra measures are needed to focus on personal and hand hygiene education in both rural and urban settings, and it would be prudent to add this in school curriculum in all ages.

Furthermore, they reported that further monitoring and strict inspection should be always maintained on food resources coming to school children, and to totally prohibit street food vendors who stray around schools and they impose risks of unsafe and unclean food to this age group who are highly susceptible to infections.

To summarize the findings of the $\mathrm{WHO}$ steering group on effects of mass preventive chemotherapy on the critical outcomes for preschool and school-age children, we followed the assessment criteria that was suggested by the WHO guideline on preventive chemotherapy to control soil-transmitted helminth infections in at-risk population groups, which was considered for each of the target groups, but here we are taking school-age children as the only category to enlist its assessment findings as this is the category examined in this study (Table 7 ).

Finally, the intervention proposed by this study is the decision-making approach that is suggested to be guiding decision-making preceding developing a mass deworming campaign in school children or populations at-risk of intestinal parasitic diseases and its burden.

The decision-making approach is abbreviated in (EDLOW), which stands for Epidemiological considerations, Demographic considerations, Logistics and resources, Opportunities and WASH measures, as follows (Figure 12):
Table 7: Summary of considerations on mass preventive chemotherapy of school-age children as enlisted by the WHO group of experts of the WHO guideline on chemotherapy to control soil-transmitted helminth infections in at-risk population groups in the light of findings of this study

Quality of - The overall quality of evidence for the effect of preventive chemotherapy

evidence on the critical outcomes for preschool and school-age children is low (According to GRADE (GRADE findings, WHO, 2017), low-quality evidence indicates that our confidence in the effect estimate is limited and the true effect may be substantially different from the estimate of the effect) (Welch et al., 2016) The overall quality of evidence for the effect of preventive chemotherapy on the critical outcomes for preschoo and school-age children is low (According to GRADE (GRADE findings, WHO, 2017), low-quality evidence indicates that our confidence in the effect estimate is limited and the true effect may be substantially different from the estimate of the effect) (Welch et al., 2016)

Balance of - Short-term, average nutritional benefits in the treated community benefits and (comprising infected and uninfected children) were not significant in the harms two reviews. The reviews found statistically significant nutritional benefits when all individuals treated are infected, which is not usually the case in deworming campaigns at Governorates with diverse range of prevalence of intestinal parasitic infections as in Egypt

- Furthermore, the review found there was no adverse events were reported in the systematic reviews and included trials

- Moderate-intensity or heavy-intensity infection causes significan species-specific morbidity among individuals infected with soiltransmitted helminth infection

- Those who have light-intensity infection are likely to derive little benefit from deworming

- Those who are not infected will gain no benefit from deworming, although safety reports also show little or no harm

Values and - There was little variability in the importance that populations assign to

preferences interventions to control soil-transmitted helminth infections

- In this study, parents favored the mass deworming medicines, and some of the interviewed campaign staff members reported that some parents asked for more deworming medicines for their other elder children

- However, there was a reported rumor going in Portsaid that the deworming medicines may affect infertility in school-age children boys

Acceptability - Preventive chemotherapy is generally widely accepted by policy-makers, health workers and teachers involved in school-based deworming program. More than 60 countries currently implement school-based programs. This also comes in agreement to the situation in Egypt, as the deworming medicines used in the campaigns (Albendazole and Mebendazole) were favorable to parents, teachers and campaigns' staff. However, the younger children found the tablet too big to be administrated or instructions of chewing the tablets were not clear, which could be reflected on less acceptability of the deworming medicines in preschool children campaigns in case of future implementation

Resource - The costs of preventive chemotherapy are largely determined by the

implication costs related to distribution and monitoring, rather than to the costs of the actual medicines

- From the perspective of distribution to children, integration with other healthcare and school-based interventions (such as during immunization days or child health days) allows this intervention to use up only minor incremental resources

- In Egypt, although the deworming medicines were donated from multinational drug pharmaceutical companies through the WHO, the operational costs were nationally provided which affected the timings of campaigns and even partially contributed (among other reasons) to the delay of the 2018 deworming campaign to be rescheduled to 2019. Furthermore, the execution of the deworming campaigns parallel to other campaigns were quite hectic to the health care providers conducting these campaigns on peripheral level, which was reported by the campaign staff enrolled in this study as the deworming campaigns came concomitantly with the 100 million lives campaigns that were also conducted nationally

Equity $\quad$ Large-scale deworming may reduce health inequities if it is an intervention that reduces disparities in levels of infections among population groups according to place of residence, income and othe social stratifiers

- In Egypt, the national mass deworming campaigns targeted schoolage children that are only in schools which suggests that children who were not attending schools were not included in the mass preventive chemotherapy. Worth to note, the Ministry of Health and Population has conducted one national deworming campaign for community schools with the support of the World Food Program in April 2017, with two doses of Albendazole separated by 2 weeks. However, this campaign was not conducted as frequent as other national regular school campaigns, and also, community schools are not a guarantee that all school-age children that are not enrolled in regular education are attending these community schools

Feasibility - The guideline development group agreed that preventive chemotherapy in children is technically feasible. Among school-age children, this is facilitated by school-based delivery systems, which are supported by ministries of health and education. This comes in agreement with the study findings. However, access to school children that are not enrolled in regular schools is a challenge, even if community schools are enrolled 


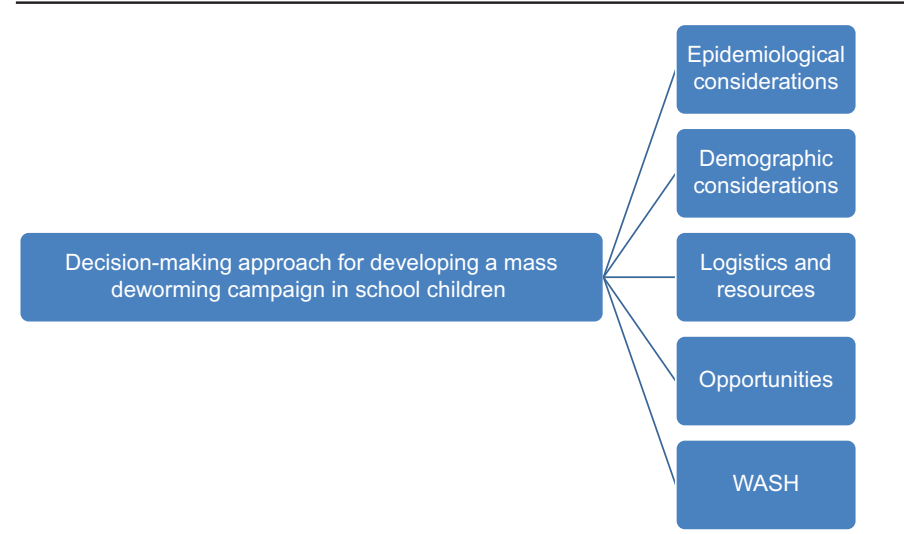

Figure 12: The EDLOW decision-making approach for mass deworming

\section{Epidemiological considerations}

- $\quad$ Prevalence higher than $20 \%$ among affected population

- Multiple endemic spots within the same geographical area

Types of parasites

- $\quad$ Burden of intestinal protozoa

- $\quad$ Multiple reported gastrointestinal outbreaks within a confined geographical area that is mostly affecting children.

\section{Demographic considerations}

- $\quad$ Age groups (preschools and school-aged children)

- Burden of disease in other susceptible populations (women of child bearing age)

- Population movement and transition factors; for example, migration and internally-displaced persons.

\section{Logistics and resources}

- $\quad$ Availability of sustainable funds

- Availability of quality deworming and antiprotozoal medicines

- $\quad$ Availability of trained health-care personnel

- Logistical feasibility in access to target populations.

\section{Opportunities}

- $\quad$ Presence of a well-established and functioning program for child health including preschool and school-age children

- $\quad$ Presence of well-established and functioning program addressing intestinal parasitic infection in adolescent women

- $\quad$ Presence of well-established and functioning program addressing intestinal parasitic infection in women of childbearing age; with special focus on pregnant women
Presence of well-established and functioning national surveillance program for intestinal parasites

Existence of a system and/or mechanism tracing children that are not enrolled in regular education and providing access to delivery of health services to them and their households Availability of deworming medicines or drugs targeting intestinal parasitic infections (helminthes and protozoa) either by sustained donation/purchasing mechanisms and/or national manufacturing.

\section{Wash}

- Well-equipped infrastructure for clean water supply in schools, nurseries, and households of affected populations

- Well-equipped infrastructure for sewage disposal in schools, nurseries, and households of affected populations.

- Elevated level of health literacy of water, sanitation, and hygiene (WASH) measures within the community

- $\quad$ Existence of a monitoring and evaluation system to maintain proper WASH infrastructure and measures within the community.

\section{Discussion}

In the review of the national activities conducted in prevention and control of intestinal parasites, it was found that the Government of Egypt represented in the Ministry of Health and Population is the main party in conducted these activities nationally. In this reference, Egypt has the basis needed for controlling infectious and/or endemic diseases which starts with the founding system that governs the prevention and control activities of such health problems and that was clear in the hierarchy of preventive medicine sector at the Egyptian Ministry of Health and Population where the Central Administration of Endemic Diseases is one of its four main operational Central Administrations.

This comes parallel to efforts exerted in combating intestinal parasites in other countries such as in South Korea for instance; where intestinal helminth infections were highly prevalent in Korea in the past, which were one of the major public health burdens in Korea during 1950s and 1960s. However, Based on the "law for Prevention of Parasitic Diseases" (Parasite Diseases Prevention Act) by the Korean Government, a national control program was implemented by targeting the school-age population in the country from 1969 to 1994 which focused on Surveillance programs, implementation of evidence-based infection prevention 
and control practices to reduce the incidence of these diseases and nationwide surveys on the prevalence of infections revealed that the egg-positive rate of helminth infections was $90.5 \%$ in 1969 , dropped to almost half (41.1\%) in 1981 till it reached $2.6 \%$ in 2012 [19].

Although Egypt did not reach to that low prevalence yet, still, we are walking on the same footsteps of countries like Korea given that both systems have started in systematically combating intestinal parasites in the 1960s.

The Egyptian methodology in combating Schistosomiasis in Egypt for long decades has been reflected in the activities directed to prevention and control of intestinal parasitic infection in general. For instance, the snail control department at the General Administration of Schistosomiasis and Intestinal Parasites was first established for Schistosomiasis snail control but was found later effective in other parasitic infections of public health importance in Egypt as in the snail control activities of $F$. hepatica [20].

Moreover, Egypt is a populous country; in fact, Egypt ranks the third in the list of most populous countries in Africa where it is preceded by Nigeria and Ethiopia, and with a world population share of $1.13 \%$ [21], where almost one-third of the Egyptian population are children, and almost $10 \%$ of the entire Egyptian population are primary-school-aged children [22], which was the category targeted by mass deworming campaigns conducted by the Egyptian Ministry of Health and Population in 2016, 2017, and 2019.

In Egypt, in a study conducted on 2016 a sample of 260 children aged between four months and 15 years, the prevalence of protozoan and helminthic infection were $21.9 \%$ and $11.9 \%$, respectively [23], while other reported prevalence rates in different parts of Egypt vary considerably from one study to another, in a study in Menia Governorate, nearly $27 \%$ of the children are suffering from intestinal parasites [24]; while the prevalence rate was $30.7 \%$ in Damietta Governorate [14], where another study reported more than 50\% prevalence in EL-Behera Governorate [20].

The difference in prevalence could be related to hygienic status as in the study of where the prevalence of intestinal parasitic infections in school age children that keep their personal hygiene was $53.19 \%$, the prevalence of intestinal parasitic infections in school age children that did not keep their personal hygiene was $67.57 \%$ [25], This result was statistically significant $(95 \% \mathrm{Cl}=0.65-0.99)$. Availability of latrine decreased the risk of intestinal parasitic infections by $66 \%(95 \%$ $\mathrm{Cl}=0.27-0.44)$. Furthermore, in the study conducted by a significantly higher prevalence rate of intestinal parasitosis was observed among students living in rural $(76.4 \%)$ than urban $(49.8 \%)$ areas [26].

In summary, mass deworming campaigns in Egypt decreased the prevalence from $21 \%$ to $2.8 \%$, which comes in consensus with results of the study of which indicates that deworming campaigns have proved effective in significantly reducing helminthic infections in most of the districts in Uganda [27].

However, there was a remarkable decline in the reported prevalence of intestinal parasitic infections after the 2016 national mass deworming campaign in Egypt, it re-increased to reach $10 \%$ within less than a year before launching the 2017 campaign. This prevalence re-rise in between national mass deworming campaigns of 2016 and 2017 in Egypt could be reflected in the current debate on deworming highlighted by the study of Centre for Evidence Synthesis in Global Health at the Liverpool School of Tropical Medicine in the United Kingdome, where they stated that the longterm societal effects of mass deworming programs for soil-transmitted helminths in low- and middle-income countries are contested [28]. In addition, in the third edition of book "Child and Adolescent Health and Development" by Bundy et al., the authors mention that although the WHO recommends Mass Drug Administration for vulnerable groups, such as children and pregnant women, who live in areas with endemic intestinal worm infection, a series of reviews from both the Cochrane Collaboration [29] and the Campbell Collaboration [30] argues that there is substantial evidence that mass deworming does not produce health benefits and therefore they do not support the use of MDA. A light was shed on the delivery of donated drugs through mass drug administration programs for soil-transmitted helminths that exceeds 1 billion doses annually shows conflicting results, and the resulting controversy has been characterized as the worm wars [31].

Despite all the efforts exerted in prevention and control of intestinal parasites in Egypt, there are still some challenges that may hinder the progress of tackling this issue on the national level; including system and operational challenges as in the shortage in physicians and paramedical personnel which may affect the annual school surveys that are supposed to be conducted at each school entry for surveying intestinal parasites, estimating prevalence and determining preventive chemotherapy needs.

Although the mass deworming medicines; either Albendazole or Mebendazole, were donated to the Egyptian Ministry of Health and Population through a WHO mechanism in accordance with the consequences of the London Declaration on Neglected Tropical Diseases announced in 2012, the operational costs are mainly covered by the Ministry of Health and Population, which is a challenge that has to be taken into consideration on regular budget determining mechanisms.

The donor fatigue is also a major challenge, as donors (mainly global pharmaceutical companies) are the only source of the donated mass deworming medicines. If the mechanism established between them and the WHO has stopped or hindered, the 
overall continuity of the mass deworming campaigns is definitely jeopardized.

Furthermore, the national mass deworming campaigns titled as campaigns against intestinal parasites, only the covered intestinal parasites were soil-transmitted helminth infections that are targeted by either Albendazole or Mebendazole, and not protozoa while protozoa have been responsible for many gastrointestinal illnesses in school age children. In addition, the prevalence alone does not provide a useful measure of potential morbidity because only a small number of infections will be associated with ill health. Instead, morbidity is related to the intensity of infection, with the most intense infections occurring in only a minority of infected individuals. As prevalence increases, the prevalence of high-intensity infections increases at a higher rate, such that high-prevalence communities experience disproportionate amounts of morbidity. Heterogeneity between communities within subnational areas was therefore approximated using modeled distributions, and the number of persons with infection intensities greater than age-dependent thresholds was estimated indirectly for each species. The frequency distributions of worms, and thus the numbers exceeding these thresholds, were estimated using negative binomial distributions that assumed general species-specific aggregation parameters based on data from Brazil, Kenya, and Uganda [32].

Deworming of school age children has been shown to reduce disease burden, especially reducing high-burden infections in a cost-effective manner, which is the measure adopted in Egypt. However, the empirical evidence from both multiyear deworming programs and modeling studies suggests that targeting school-age children alone for preventive chemotherapy are insufficient for sustained control and elimination of soil-transmitted helminth infection [33]. Indeed, in many settings, adults are at particularly high risk of hookworm infection and thus contribute substantially to transmission [34].

Although there is no concrete evidence on development of antimicrobial resistance in humans after administrating mass deworming medicines, still, experience from the veterinary sector demonstrated that antihelminthic drug resistance developed after years of large-scale monotherapy. The anticipated development of antimicrobial resistance is a challenge that has to be taken into consideration for prevention and control policies that adopt mass deworming campaigns as a long-term preventive measure against intestinal parasites [35].

The mass deworming campaigns have been shown to provide health benefits for the recipients and have demonstrated value for endemic communities today, but these mass deworming campaigns alone have yet to be shown to provide a long-term solution. Historical experience in previously endemic countries, including Europe, the USA, Japan, and South Korea, has shown that these infections can be effectively and sustainably controlled in the long-term through environmental interventions. Moreover, improvements in WASH will continue to be a major policy objective beyond the goal of reducing intestinal parasitic infection, due to its wide-ranging impacts on other diseases, society, and well-being [36].

\section{References}

1. Okyay P, Ertug S, Gultekin B, Onen O, Beser E. Intestinal parasites prevalence and related factors in school children, a western city sample-Turkey. BMC Public Health. 2004;4(1):64. http://doi.org/10.1186/1471-2458-4-64

PMid:15615592

2. Kumma WP, Meskele W, Admasie A. Prevalence of intestinal parasitic infections and associated factors among food handlers in Wolaita Sodo University students caterings, Wolaita Sodo, Southern Ethiopia: A cross-sectional study. Front Public Health. 2019;7:140. http://doi.org/10.3389/fpubh.2019.00140 PMid:31214560

3. Zebardast N, Gharavi MJ, Abadi A, Tabaei SJ, Yeganeh F, Khazan $\mathrm{H}$, et al. Frequency of intestinal parasites in patients with gastrointestinal disorders, in different parts of Iran during 2012-2013. Int J Enteric Pathog. 2015;3(1):1-5. http://doi. org/10.17795/ijep22682

4. Centers for Disease Control and Prevention. Webpage Parasites Home, Parasites, Information for Specific Groups, Children; 2020. Available from: https://www.cdc.gov/parasites/ children.html [Last accessed on 2020 Jan 03].

5. Mabbott NA. The influence of parasite infections on host immunity to co-infection with other pathogens. Front Immunol. 2018;9:2579. http://doi.org/10.3389/fimmu.2018.02579

PMid:30467504

6. Hemphill A, Müller N, Müller J. Comparative pathobiology of the intestinal protozoan parasites Giardia lamblia, Entamoeba histolytica, and Cryptosporidium parvum. Pathogens. 2019;8(3):116.

PMid:31362451

7. Haque R. Human intestinal parasites. J Health Popul Nutr. 2007;25(4):387-91.

PMid:18402180

8. Ramana KV. Intestinal parasitic infections: An overview. Ann Trop Med Public Health. 2012;5(4):279.

9. Steketee RW. Pregnancy, nutrition and parasitic diseases. J Nutr. 2003;133(5):1661S-7S. http://doi.org/10.1093/jn/133.5.1661S PMid:12730482

10. Coulibaly JT, Fürst T, Silué KD, Knopp S, Hauri D, Ouattara M, et al. Intestinal parasitic infections in schoolchildren in different settings of Côte d'Ivoire: Effect of diagnostic approach and implications for control. Parasit Vectors. 2012;5(1):135. http:// doi.org/10.1186/1756-3305-5-135

PMid:22768986

11. Bethony J, Brooker S, Albonico M, Geiger SM, Loukas A, Diemert D, et al. Soil-transmitted helminth infections: Ascariasis, trichuriasis, and hookworm. Lancet. 2006;367(9521):1521-32. http://doi.org/10.1016/S0140-6736(06)68653-4 PMid:16679166

12. Nematian J, Nematian E, Gholamrezanezhad A, Asgari AA Prevalence of intestinal parasitic infections and their relation 
with socio-economic factors and hygienic habits in Tehran primary school students. Acta Trop. 2004;92(3):179-86. http:// doi.org/10.1016/j.actatropica.2004.06.010

PMid:15533285

13. Bieri FA, Gray DJ, Williams GM, Raso G, Li YS, Yuan L, et al. Health-education package to prevent worm infections in Chinese schoolchildren. N Engl J Med. 2013;368(17):1603-12. http://doi.org/10.1056/NEJMoa1204885 PMid:23614586

14. Monib ME, Hassan AA, Attia RA, Khalifa M. Prevalence of intestinal parasites among children attending Assiut University Chil-dren's hospital, Assiut, Egypt. J Adv Parasitol. 2016;3(4):125-31.

15. The World Health Organization Website, Neglected Tropical Diseases; Diseases. Geneva: World Health Organization; 2020.

16. The World Health Organization, The Global Health Observatory, World Health Data Platform Indicators; Density of Health and Social Workforce. Geneva: World Health Organization; 2020.

17. The World Health Organization. Guideline: Preventive Chemotherapy to Control Soil-Transmitted Helminth Infections in at-Risk Population Groups. Geneva: World Health Organization; 2017.

18. Ministry of Health and Population/Egypt, El-Zanaty and Associates/Egypt, and ICF International. 2015. Egypt Demographic and Health Survey 2014. Cairo, Egypt: Ministry of Health and Population and ICF International; 2014

19. Bahk YY, Shin EH, Cho SH, Ju JW, Chai JY, Kim TS. Prevention and control strategies for parasitic infections in the Korea centers for disease control and prevention. Korean J Parasitol. 2018;56(5):401-8. http://doi.org/10.3347/kjp.2018.56.5.401 PMid:30419725

20. Haggag AA, Rabiee A, Abd Elaziz KM, Gabrielli AF, Abdelhai R, Hashish A, et al. Elimination of schistosomiasis haematobia as a public health problem in five governorates in Upper Egypt. Acta Trop. 2018;188:9-15. http://doi.org/10.1016/j. actatropica.2018.08.024 PMid:30145259

21. The World Meters Report, Populations, African Countries by Population for 2020; 2020.

22. CAMPAS Statement Marking World Children's Day, Egypt CAPMAS, Ahram Online, Monday 20 Nov; 2017.

23. Mahmud MA, Spigt M, Bezabih AM, Pavon IL, Dinant GJ, Velasco RB. Efficacy of handwashing with soap and nail clipping on intestinal parasitic infections in school-aged children: A factorial cluster randomized controlled trial. PLoS Med. 2015;12(6):e1001837. http://doi.org/10.1371/journal. pmed.1001837

PMid:26057703

24. Ibrahium FA. Prevalence and predisposing factors regarding intestinal parasitic infections among rural primary school pupils at Minia Governorate, Egypt. J Public Health Afr. 2011;2(2):e29. http://doi.org/10.4081/jphia.2011.e29 PMid:28299070

25. Feleke BE. Nutritional status and intestinal parasite in school age children: A comparative cross-sectional study. Int J Pediatr. 2016;2016:1962128. http://doi.org/10.1155/2016/1962128 PMid:27656219

26. Sitotaw B, Shiferaw W. Prevalence of intestinal parasitic infections and associated risk factors among the firstcycle primary schoolchildren in Sasiga District, Southwest
Ethiopia. J Parasitol Res. 2020;2020:8681247. https://doi. org/10.1155/2020/8681247

27. Adriko M, Tinkitina B, Arinaitwe M, Kabatereine NB, Nanyunja M, Tukahebwa EM. Impact of a national deworming campaign on the prevalence of soil-transmitted helminthiasis in Uganda (2004-2016): Implications for national control programs. PLoS Negl Trop Dis. 2018;12(7):e0006520. https://doi.org/10.1371/ journal.pntd.0006520 PMid:29975696

28. Jullien $S$, Sinclair D, Garner P. The impact of mass deworming programmes on schooling and economic development: An appraisal of long-term studies. Int J Epidemiol. 2016;45(6):2140-53. https://doi.org/10.1093/ije/dyw283

PMid:28161712

29. Taylor-Robinson DC, Maayan N, Soares-Weiser K, Donegan S, Garner P. Deworming drugs for soil-transmitted intestinal worms in children: Effects on nutritional indicators, haemoglobin, and school performance. Cochrane Database Syst Rev. 2015;7:CD000371. https://doi.org/10.1002/14651858. CD000371.pub6

PMid:26202783

30. Welch VA, Awasthi S, Cumberbatch C, Fletcher R, McGown J, Merritt $\mathrm{K}$, et al. Deworming and adjuvant interventions for improving the developmental health and well-being of children in low- and middle-income countries: A systematic review and meta-analysis. Campbell Syst Rev. 2016;12:1-7. https://doi. org/10.4073/csr.2016.7

31. Bundy DA, Appleby LJ, Bradley M, Croke K, Hollingsworth TD, Pullan R, et al. Mass deworming programs in middle childhood and adolescence. In: Child and Adolescent Health and Development. $3^{\text {rd }}$ ed. Washington, DC: The International Bank for Reconstruction and Development/The World Bank; 2017. https://doi.org/10.1596/978-1-4648-0423-6_ch13 PMid:30212135

32. Pullan RL, Smith JL, Jasrasaria R, Brooker SJ. Global numbers of infection and disease burden of soil transmitted helminth infections in 2010. Parasit Vectors. 2014;7(1):37. PMid:24447578

33. TruscottJE, TurnerHC, Farrell SH,Anderson RM. Soil-transmitted helminths: Mathematical models of transmission, the impact of mass drug administration and transmission elimination criteria. Adv Parasitol. 2016;94:133-98. https://doi.org/10.1016/ bs.apar.2016.08.002

PMid:27756454

34. Brooker S, Marriot H, Hall A, Adjei S, Allan E, Maier C, et al. Community perception of school-based delivery of anthelmintics in Ghana and Tanzania the partnership for child development. Trop Med Int Health. 2001;6(12):1075-83. https://doi. org/10.1046/j.1365-3156.2001.00806.x PMid: 11737845

35. Geerts S, Gryseels B. Drug resistance in human helminths: Current situation and lessons from livestock. Clin Microbiol Rev. 2000;13(2):207-22. https://doi.org/10.1128/CMR.13.2.207 PMid: 10755998

36. Nery SV, Pickering AJ, Abate E, Asmare A, Barrett L, BenjaminChung $\mathrm{J}$, et al. The role of water, sanitation and hygiene interventions in reducing soil-transmitted helminths: Interpreting the evidence and identifying next steps. Parasit Vectors. 2019;12(1):273. 